\title{
THE
}

\section{Multiple Roles of Specialized Literacy Professionals: The ILA 2017 Standards}

Rita M. Bean

Diane Kern

University of Rhode Island, dkern@uri.edu

Follow this and additional works at: https://digitalcommons.uri.edu/education_facpubs

The University of Rhode Island Faculty have made this article openly available.

Please let us know how Open Access to this research benefits you.

This is a pre-publication author manuscript of the final, published article.

Terms of Use

This article is made available under the terms and conditions applicable towards Open Access

Policy Articles, as set forth in our Terms of Use.

\section{Citation/Publisher Attribution}

Bean, R.M., \& Kern, D. (2018). Multiple Roles of Specialized Literacy Professionals: The ILA 2017

Standards. The Reading Teacher, 71( 5), 615- 621. doi: 10.1002/trtr.1671

Available at: https://doi.org/10.1002/trtr.1671 


\section{Multiple Roles of Specialized Literacy Professionals: The ILA 2017 Standards}

Marshall McLuhan once commented that too often "we drive forward looking into the rearview mirror." In other words, as we reflect about our role responsibilities, we think about the successes we have had in fulfilling our responsibilities, and how comfortable we are with the status quo. We ask ourselves, why change? For example, as reading/literacy specialists, we enjoy our work with students in a pull-out setting where we have materials, a comfortable nook for teaching, and the chance to work one-on-one with students. As literacy coaches, we value our work with novice teachers who are eager to receive our support. Yet educational needs are changing, and with it the ways that specialized literacy professionals, such as reading specialists and literacy coaches, function in schools.

The Standards for the Preparation of Literacy Professionals 2017 (Standards 2017; International Literacy Association, 2018) were developed to address these needs. They reflect current research and literature about literacy, professional learning, and the important roles of the many professionals involved with literacy instruction (e.g., classroom teachers, principals, teacher educators). The focus in this article is on the role of specialized literacy professionals in schools, specifically, reading/literacy specialists, literacy coaches, and literacy coordinators/supervisors.

The 2017 standards can be useful to many different audiences. They provide guidelines for universities and colleges who prepare specialized literary professionals. They can also serve as a tool for state departments developing regulations for credentialing literacy professionals or for school districts who are hiring or developing job descriptions for them. Further, the standards 
can be helpful to those serving as specialized literacy specialists in schools as they highlight what these professionals need to know and be able to do to be effective in their positions. The purposes of this article are to: (1) compare the 2017 standards with the previous 2010 standards, (2) describe the levels of emphases for each role, and (3) identify implications of these new standards for specialized literacy professionals in today's schools.

\section{What's the Same?}

The purpose of the 2017 standards, like the 2010 standards, is the same; that is, they describe high-level, rigorous expectations for those preparing or credentialing specialized literacy professionals to work in Pre-K-12 schools. Both sets of standards were developed by a representative group of literacy educators and researchers knowledgeable about the roles of specialized literacy professionals. Both 2010 and 2017 standards are based on the assumptions that specialized literacy professionals have an initial teaching certificate and are seeking advanced preparation in the area of literacy. Further, the standard themes remain essentially the same (e.g., Foundational Knowledge, Curriculum and Instruction), however, the content has been revised. In Figure 1, we list the seven standards as described Standards 2017. More indepth information can be found in Standards 2017: www.literacyworldwide.org/getresources/standards.

$<$ Insert Figure 1>

\section{What Are the Differences?}

Two major shifts that influenced the 2017 standards are described as follows.

\section{Shift 1: From Reading to Literacy}


The acknowledgment that reading performance is enhanced when teachers take into consideration the ways that the literacy components (reading, writing, listening, speaking, and viewing) are related and how each builds on the other has led to changes in thinking about how students develop literacy skills and how literacy is taught in schools from the early grades through high school. This shift has created a need for those preparing specialized literacy professionals and candidates themselves to become more knowledgeable about all aspects of literacy, defined by the International Literacy Association (ILA) as "the ability to identify, understand, interpret, create, compute, and communicate using visual, audible, and digital materials across disciplines and in any context."

\section{Shift 2: Specialized Literacy Professionals: A New Term}

In the 2017 standards, "specialized literacy professionals" serves as an overarching or umbrella term to describe three major roles in schools today: reading/literacy specialist, literacy coach, and school literacy coordinator/supervisor. Given research evidence that indicates distinctions in these roles (Bean, Kern, et al., 2015; Galloway \& Lesaux, 2014), the goal was to identify more clearly the responsibilities of each of these professionals, and the necessary knowledge, skills, and dispositions necessary for them to be successful. One of the most significant changes in the standards is the separation of the role of reading specialist from the literacy coach (i.e., in the 2010 standards, there was a single category, that of reading specialist/literacy coach). Given the prevalence of literacy coaches in schools and the greater expectations for working directly with teachers, the need to "sharpen the terminology" (Galloway \& Lesaux, 2014) has become more essential. The 2017 Standards Revision Committee followed the recommendations in the position statement and research brief (ILA, 2015a; ILA, 2015b) in which the following division of responsibilities was described: 


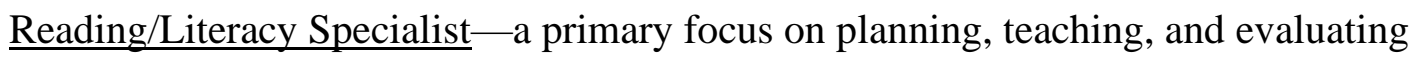
instruction for students experiencing difficulties with reading and writing

Literacy Coach - a primary focus on improving classroom instruction by supporting teacher learning and facilitating school literacy program efforts

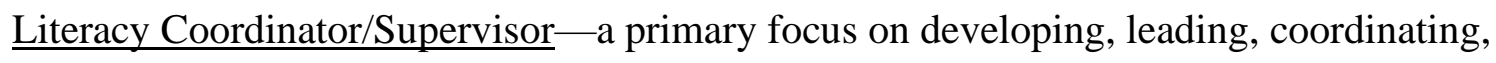
and evaluating the school or district literacy program

The distinctions in roles should be useful to many audiences. School districts can gain a better understanding of the primary function of these distinct role-groups, which should be useful to them in hiring personnel. Universities and colleges will be able to focus their programming for reading/literacy specialists and consider creating credentialing programs for preparing coaches or coordinators. Candidates themselves can develop a clearer perspective about what it is they are being prepared to do as a reading/literacy specialist, literacy coach, or literacy coordinator/supervisor. The new standards provide a vision for thinking about what specialized literacy professionals can do to improve literacy instruction; in other words, a means for looking through the front window rather than through the rearview mirror.

\section{Levels of Emphasis}

One of the ways to distinguish between and among the roles is to think about the emphases or primary focus of each role-group (see Figure 2). The primary focus for the reading/literacy specialist (RLS) is the student; however, the role also requires that the RLS work with teachers and also have some understanding of the system in which they work. he primary emphasis of the literacy coach (LC) is the teacher, but to be effective, LCs must understand how to work effectively within the system, and some might have teaching responsibilities. The 
literacy coordinator/supervisor's (LCS) primary focus is that of the system. At the same time, the LCS will most likely work with teachers (e.g., providing professional development), and some may have instructional responsibilities.

\section{<Insert Figure 2>}

In other words, all three role groups may have some of the same responsibilities, but the emphasis for each generally differs. However, we recognize that in reality, the distinctions are not as clear-and professionals may wear multiple hats that differ by school or district. In other words, there are reading specialists who have some coaching responsibilities, without the title of coach. Likewise, there are literacy coaches who work half time as coach and half time as a reading specialist/interventionist. There are many reasons for this, including financial exigencies, preferences of school leaders as to what roles might be most beneficial in improving student literacy learning, and even the experiences and background of literacy professionals themselves. For example, those with less classroom teaching experiences may feel more comfortable working with students than with their peers, whereas those with more teaching experience may find themselves working more closely with teachers as a means of improving overall school literacy learning.

\section{What Professionals in All Roles Should Know and Be Able to Do: Expectations of the 2017 Standards}

In the following, we provide implications for this shift in role-expectations that we believe can be useful for specialized literacy professionals in schools, regardless of role or responsibilities. Although many of these implications are related to Standard 6, Professional Learning and Leadership, there are several that address expectations for other standards. 


\section{Gaining Trust}

Regardless of role, the literacy professional must be able to develop trust, not only with teachers but also with the principal and other administrators. Without trust, little can happen: Teachers hesitate to work with the literacy specialist or literacy coach when there is confusion about the role, or teachers feel they are being judged or evaluated. Ideas for gaining trust include the following:

- Start the school year by holding individual conversations with teachers about their goals for their students and literacy learning. Such conversations help the literacy professional learn more about the beliefs, knowledge, strengths, needs, and interests of the teacher, and establish some direction for future work.

- Be an active listener. Literacy professionals should adhere to a 80-20 rule, that is, they should be listening 80 percent of the time and talking about 20 percent of the time. They should understand how to use elaboration, rephrasing, asking for clarification, and summarizing to encourage teacher talk (Bean, 2014; Bean \& Ippolito, 2016).

- Be respectful. Teachers have important information to share; literacy professionals can acknowledge this by asking questions and showing interest in what the teacher is saying by responding positively (e.g., smiling, nodding). Think about how to make each teacher feel important!

- Be accessible. It's difficult to build trust if the literacy professional is not available or does not follow through as promised. There are times when a change in schedule is unavoidable, but it's important to inform the teacher, explain why, and reschedule.

- Be passionate about what you do. When a problem arises, be the first to step in and help solve it. 


\section{Establishing a Working Relationship With the Principal}

Numerous studies (Bean, Dole, Nelson, Belcastro, \& Zigmond, 2015; Bean \& Lillenstein, 2012; Matsumura, Garnier, Correnti, Junker, \& Bickel, 2010) have highlighted the fact that literacy professionals need to work closely with the principal if they are to be successful in their roles. Principals have the power to make things happen, and they also serve as gatekeepers who can limit specific change efforts. If principals don't schedule time for teachers to work together with the literacy specialist, or coach, little can be achieved. Ideas for establishing a strong relationship with the principal follow:

- Develop with the principal a clear description of your job responsibilities. Discuss questions such as these: In what ways can you, as a reading/literacy specialist support classroom instruction? Should you coplan and coteach with classroom teachers? If so, is time available for you and the teachers to meet? As a coach, should you work only with teachers who request your support or with all teachers? Do you as literacy coordinator have evaluation responsibilities, and if so, what model of teacher evaluation should be used?

- Develop with the principal times and ways of communicating. You may have regularly scheduled meetings once or twice a month but meet informally as needed. You might also communicate electronically on a regular basis, describing your focus, raising questions or concerns, suggesting possible solutions to problems.

- Share current information about literacy research with the principal to keep him or her up to date. (Standard 1: Foundational Knowledge).

- Be honest about your needs as a literacy professional. If you feel you are being taken away from your responsibilities (e.g., being asked to substitute teach on a regular basis, 
entering test data of students), talk with the principal about how such activities make you less effective; show the principal what you have not been able to do (missed coteaching in the classroom of three teachers this past week). Problem solve with the principal (e.g., perhaps an administrative assistant or a volunteer might enter test data).

- Keep a journal of your activities to share with the principal. The principal may be evaluating your work, and evidence you have about what you have been doing can be helpful to the principal.

\section{Understand the Ways in Which Culture Affects Your Role and Ways You Can Affect the Culture}

Research findings indicate that culture has a tremendous effect on the potential effectiveness of specialized literacy professionals (Bean \& Lillenstein, 2014; Hunt \& Handsfield 2013; Lesaux \& Marietta, 2011). Specialized literacy professionals who understand how adults learn and how to effect change in the culture of their school can make a difference. In collaboration with others, they can create an environment in which schools are places of learning for students and teachers (Bean \& Swan Dagen, 2014). Such work requires the specialized literacy professional to work with groups as well as with individual teachers. As stated by Mangin and Dunsmore (2015), "the sum of individual changes across teachers is not equivalent to systemic reform" (p. 203). Ideas for developing school culture follow:

- Become familiar with how to facilitate group meetings. This means understanding how to lead groups and how to be an effective group member. The protocols found on the School Reform Initiative website (www.schoolreforminitiative.org) are useful tools for those working with groups; they can assist in building a sense of team and in providing a structure for problem solving. Books that have useful information about 
working with groups include Cultivating Coaching Mindsets: An Action Guide for Literacy Leaders (Bean \& Ippolito, 2016) and The Art of Coaching Teams: Building Resilient Communities That Transform Schools (Aguilar, 2017).

- Understand your own beliefs and attitudes about literacy and learning as a means of developing a better sense of how they influence your work with others. Also, recognize that others have beliefs and attitudes that affect the ways in which they work with you. Think about how you can help others develop a sense of their own beliefs and how these affect their teaching and learning.

\section{Continue to Be a Lifelong Learner}

Much has changed in how literacy is taught in schools. The 2017 standards reflect this new knowledge and affect the ways in which specialized literacy professionals work in schools and how they are prepared. In the following, we focus on three areas to illustrate the ways in which the standards necessitate the need to be lifelong learners.

Assessment and Evaluation (Standard 3): The emphasis in the 2017 standards is on the use of assessment to inform instruction as well as accountability. This standard calls for specialized literacy professionals to have a deep understanding of the purposes, attributes, strengths, and limitations of assessment tools. Specialized literacy professionals need a deep understanding of what various assessments provide and do not provide in terms of information about students' literacy strengths and needs. Specialized literacy professionals should be able to:

- Select, administer, and interpret literacy assessment measures, both formal and informal, that can inform instructional practice. Sharing the results of assessments with classroom teachers as a means of influencing instruction is an integral aspect of this work. 
- Lead professional learning experiences that provide colleagues with the information they need to use the results in meaningful, accurate ways. Such professional learning should also emphasize the importance of student self-assessment as a key tool.

- Advocate for students by explaining the results of assessment tools with stakeholders, including students, families, teachers, and others.

Diversity and Equity (Standard 4): As the United States becomes more diverse, so do U.S. schools and the students they serve. In the 2017 standards, we highlight the importance of candidates not only having a strong knowledge of the relevant theories and research underlying diversity and equity but also demonstrating the ability to teach in ways that respect what students bring to the classrooms, and facilitate teacher efforts to do likewise. Specialized literacy professionals also serve as advocates for their students at the classroom, school, district, and community levels. Implications include:

- Engaging in reflective practice about your own belief systems and the biases you bring to the school; supporting teachers in the same sort of reflection.

- Sharing resources and approaches that help teachers understand how to provide culturally responsive instruction. Several possible sources include Culturally Responsive Teaching (Gay, 2010); The Dreamkeepers: Successful Teachers of African American Children (Ladson-Billings, 2009); and "The Role of Culture in Literacy, Learning, and Teaching” (Li, 2011).

\section{Learners and the Literacy Environment (Standard 5): Included in Standard 5 are} expectations for integrating technology into the literacy curriculum. As evident in everyday life, technology has had an enormous effect on the way we live, work, and learn. The 2017 standards 
require specialized literacy professionals to be able to use and support teachers in using a variety of print and digital materials to engage and motivate all learners. They must be able to integrate digital technologies into the curriculum in appropriate, safe, and effective ways. Implications include:

- Developing an awareness of the various digital options available for teaching and for learning — and review these critically before using them with students.

- Taking into consideration the need to provide for student choice and expanding students' access to a range of literacy materials

- Looking for ways to integrate various types of text and other modalities (e.g., image, audio, drawing, voice) in instructing students; sharing those ideas with teachers.

There are other aspects of the standards not described in this article that provide important information for professionals in the field and those who prepare them. Therefore, readers interested in specific aspects of literacy instruction or assessment may want to consult the full Standards 2017. Those who prepare specialized literacy professionals may want to look closely at Standard 7, which describes more fully the recommended practicum experiences.

\section{Be Nimble!}

All the implications described earlier can be helpful to those involved with literacy learning; this one is probably one of the most important to remember. As mentioned previously, although the 2017 standards emphasize the distinctions between the roles, various factors will influence the ways in which professionals function in schools Therefore, although you may be hired for a position with the title "reading/literacy specialist," you may be asked to spend some of your time serving as a coach, leading a data analysis team, or facilitating professional learning 
activities. You may indeed wear multiple hats! This suggests that those leading preparation programs should think about how they might diversify their programs to allow for this multiplicity of roles (Galloway \& Lesaux, 2014). Ideas for those in the field follow:

- Be honest with administrators, letting them know whether you feel prepared to assume certain responsibilities, especially if given new tasks. Workload responsibilities might need to change.

- Think about taking a class or attending a workshop that will provide you with necessary knowledge or skills.

- Ask for a mentor, such as a fellow coach, whom you can shadow or work with to get a sense of your new role.

- Make sure teachers understand the new role. The principal might describe your responsibilities to teachers, highlighting changes that might affect teachers (e.g., no longer pulling out students from classrooms).

Every new responsibility brings challenges and new opportunities that enable you to grow professionally - thus, the notion of being nimble, that is, prepared to move quickly and adroitly to assume these new responsibilities.

\section{Looking Forward-Out the Front Window}

This is an exciting time for educators, especially for literacy professionals as they address the key shifts in literacy instruction, the challenges of societal change, and the impact of technology on teaching and learning. The 2017 standards provide an important message to specialized literacy professionals and to those who prepare them. This message highlights the key ways in which literacy professionals can influence school improvement, especially as related 
to literacy assessment and instruction. This message also reinforces the importance of literacy professionals working collaboratively with other educators and those in the community to improve literacy instructional practices and student learning. The 2017 standards are forward looking; they ask for a new way of thinking that requires looking out the front window.

\section{References}

Aguilar, E. (2017). The art of coaching teams: Building resilient communities that transform schools. San Francisco, CA: Jossey-Bass.

Bean, R.M. (2014). The reading specialist: Leadership for the classroom, school, and community (3rd ed.). New York, NY: Guilford.

Bean, R.M., Dole, J.A., Nelson, K.L., Belcastro, E.G., \& Zigmond, N. (2015). The sustainability of a national reading reform initiative in two states. Reading \& Writing Quarterly: Overcoming Learning Difficulties, 31(1), 30-55.

Bean, R.M., \& Ippolito, J. (2016). Cultivating coaching mindsets: An action guide for literacy leaders. West Palm Beach, FL: Learning Sciences International; Newark, DE: International Literacy Association.

Bean, R., Kern, D., Goatley, V., Ortlieb, E., Shettel, J., Calo, K.,...Cassidy, J. (2015). Specialized literacy professionals as literacy leaders: Results of a national survey. Literacy Research and Instruction, 54(2), 1-32. https://doi:10.1080/19388071.2014.998355

Bean, R.M., \& Lillenstein, J. (2012). Response to intervention and the changing roles of schoolwide personnel. The Reading Teacher, 6(7) 491-501. 
Bean, R.M., \& Swan Dagen, A. (2014). Schools as places of learning: The powerful role of literacy leaders. In R.M. Bean \& A. Swan Dagen (Eds.), Best practices of literacy leaders: Keys to school improvement (pp. 355-378). New York, NY: Guilford.

Galloway, E.P.. \& Lesaux, N.K. (2014). Leader, teacher, diagnostician, colleague, and change agent: A synthesis of the research on the role of the reading specialist I this era of RTIbased literacy reform. The Reading Teacher, 67(7), 517-526.

Gay, G. (2010). Culturally responsive teaching (2nd ed.). New York, NY: Teachers College Press.

Hunt, C.S., \& Handsfield, L.J. (2013). The emotional landscapes of literacy coaching: Issues of identity, power, and positioning. Journal of Literacy Research, 45(1), 47-86.

International Literacy Association. (2015a). The multiple roles of school-based specialized literacy professionals [Position statement]. Newark, DE: Author.

International Literacy Association. (2015b). The multiple roles of school-based specialized literacy professionals [Research brief]. Newark, DE: Author.

Ladson-Billings, G. (2009). The dreamkeepers: Successful teachers of African American children (2nd ed.). San Francisco, CA: Jossey-Bass.

Lesaux, N.K., \& Marietta, S.H. (2011). Making assessment matter: Using test results to differentiate reading instruction. New York, NY: Guilford.

Li, G. (2011). The role of culture in literacy, learning, and teaching. In M. Kamil, P.D. Pearson, E.B. Moje, \& P. Afflerbach (Eds.), Handbook of reading research (Vol. 4, pp. 515-537). New York, NY: Routledge. 
Mangin, M.M., \& Dunsmore, K. (2015). How the framing of instructional coaching as a lever for systemic or individual reform influences the enactment of coaching. Educational Administration Quarterly, 51(2), 179-213.

Matsumura, L., Garnier, H.E., Correnti, R., Junker, B., \& Bickel, D.D. (2010). Investigating the effectiveness of a comprehensive literacy coaching program in schools with high teacher mobility. The Elementary School Journal, 111(1), 35-62.

McLuhan, M., \& Fiore, Q. (1967). The medium is the message: An inventory of effects. New York, NY: Penguin. 
Figure 1. 2017 ILA Standards (Overall Description of Standards for All Roles

\section{Standard 1: Foundational Knowledge}

Candidates demonstrate knowledge of the theoretical, historical, and evidence-based foundations of reading, writing, language, speaking, listening, viewing and the integral role of literacy professionals in schools.

\section{Standard 2: Curriculum and Instruction}

Candidates use foundational knowledge to critique and implement literacy curricula to meet needs of learners, design and implement, with colleagues, small-group and individual evidencebased literacy instruction for learners with specific literacy needs.

\section{Standard 3: Assessment and Evaluation}

Candidates understand, select, and use valid, reliable, fair, and appropriate assessment tools to screen, diagnose, and measure student literacy achievement; inform instruction and evaluate interventions; participate in professional learning experiences; explain assessment results and advocate for appropriate literacy practices to relevant stakeholders.

\section{Standard 4: Diversity and Equity}

Candidates demonstrate knowledge of research, relevant theories, pedagogies, essential concepts of diversity and equity; demonstrate and provide opportunities for understanding all forms of diversity as central to students' identities; create classrooms and schools that are inclusive and affirming; advocate for equity at school, district, and community levels.

\section{Standard 5: Learners and the Literacy Environment}

Candidates meet the developmental needs of all learners and collaborate with school personnel to use a variety of print and digital materials to engage and motivate all learners; integrate 
digital technologies in appropriate, safe, and effective ways; foster a positive climate that supports a literacy-rich learning environment.

\section{Standard 6: Professional Learning and Leadership}

Candidates recognize the importance of, participate in, and facilitate ongoing professional learning as part of career-long leadership roles and responsibilities.

\section{Standard 7: Practicum/Clinical Experiences}

Candidates apply theory and best practice in multiple supervised practicum/clinical experiences.

Figure 2. Levels of Emphases
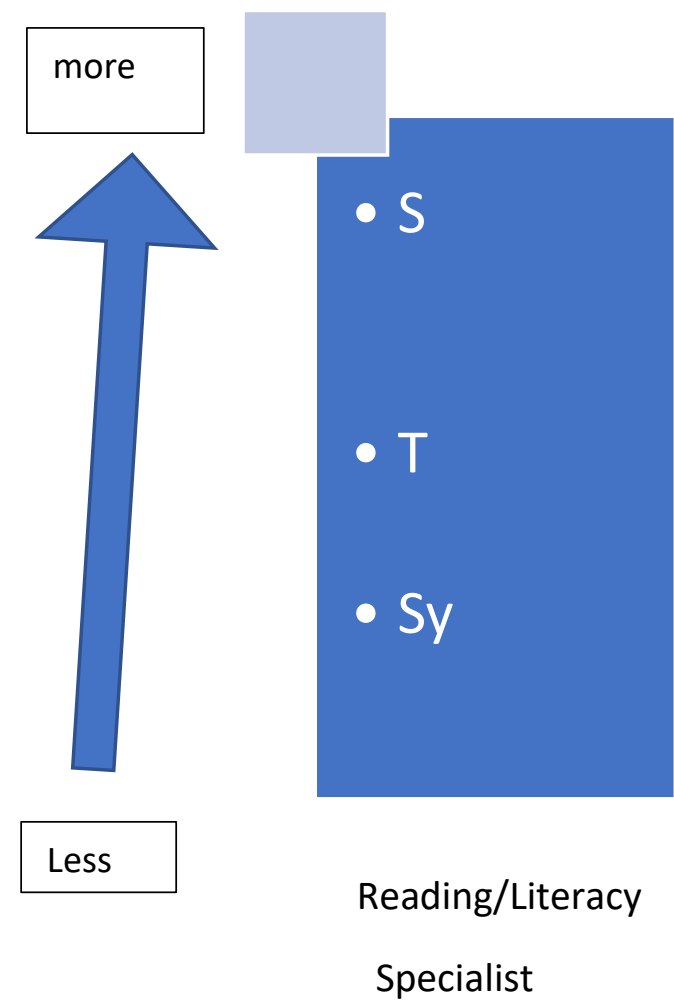

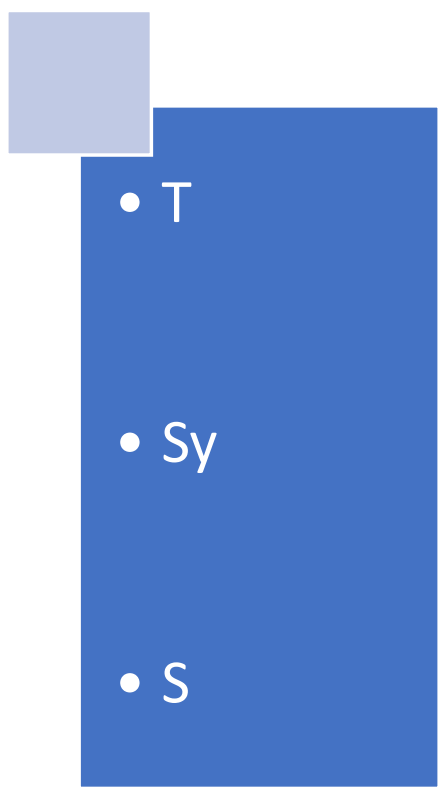

Literacy Coach

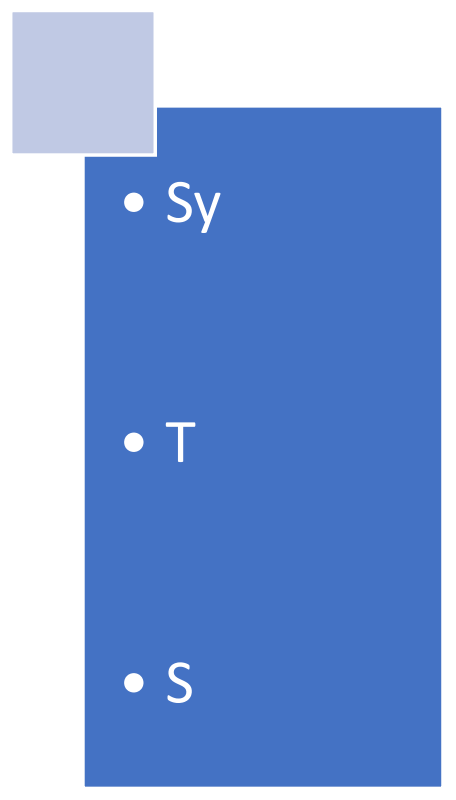

Literacy Coordinator/

Supervisor

Sy $=$ System

Code: $S=$ Students

$\mathrm{T}=$ Teachers 